\title{
Andrographolide ameliorates d-galactosamine/lipopolysaccharide- induced acute liver injury by activating Nrf2 signaling pathway
}

\author{
Chen-wei Pan ${ }^{1, *}$, Shou-xing Yang ${ }^{2, *}$, Zhen-zhen Pan ${ }^{3, *}$, Bo Zheng ${ }^{2}$, Jian-zhang Wang ${ }^{2}$, \\ Guang-rong Lu ${ }^{2}$, Zhan-xiong $X_{\mathrm{Cu}^{2}}$ and Chang-long $\mathrm{Xu}^{2}$ \\ ${ }^{1}$ Department of Infectious Disease, The Second Affiliated Hospital and Yuying Children's Hospital of Wenzhou Medical \\ University, Wenzhou, Zhejiang, 325027, China \\ ${ }^{2}$ Department of Gastroenterology, The Second Affiliated Hospital and Yuying Children's Hospital of Wenzhou Medical \\ University, Wenzhou, Zhejiang, 325027, China \\ ${ }^{3}$ Department of Infectious Disease, The First Affiliated Hospital of Wenzhou Medical University, Wenzhou, Zhejiang, 325027, China \\ *Chen-wei Pan, Shou-xing Yang and Zhen-zhen Pan are co-first authors \\ Correspondence to: Zhan-xiong Xue, email: xuezhanxiong@126.com \\ Chang-long XU, email: xchlong@163.com \\ Keywords: andrographolide, LPS, D-GalN, Nrf2, NF-KB \\ Received: February 28, $2017 \quad$ Accepted: March 28, $2017 \quad$ Published: April 17, 2017 \\ Copyright: Pan et al. This is an open-access article distributed under the terms of the Creative Commons Attribution License 3.0 \\ (CC BY 3.0), which permits unrestricted use, distribution, and reproduction in any medium, provided the original author and source \\ are credited.
}

\section{ABSTRACT}

Andrographolide (ADH), a diterpenoid lactone extracted from Andrographis paniculata, has been found to have anti-inflammatory and anti-oxidative effects. However, its protective effects and mechanisms on liver injury have not been investigated clearly. This study takes an attempt to reveal the protective effects and mechanism of ADH on lipopolysaccharide (LPS) and D-galactosamine (D-GaIN)-induced acute liver injury in mice. The mice liver injury model was induced by LPS $(60 \mathrm{mg} / \mathrm{kg})$ and D-GalN $(800 \mathrm{mg} /$ $\mathbf{k g}$ ), and ADH was given $1 \mathrm{~h}$ after LPS and D-GalN treatment. Hepatic tissue histology was measured by H\&E staining. Serum alanine aminotransferase (ALT) and aspartate aminotransferase (AST) levels were detected by detection kits. The levels of TNF- $\alpha$ and IL-1 $\beta$ were detected by ELISA. Moreover, malondialdehyde (MDA) and reactive oxygen species (ROS) contents were also detected. Meanwhile, the expression of Nrf2, HO-1, and NF-кB were detected by western blot analysis. The results showed that ADH treatment improved liver histology and decreased the levels of ALT, AST, MPO, IL-1, TNF-, as well as MDA and ROS levels of hepatic tissues in a dose-dependent manner. ADH also inhibited LPS/D-GalN-induced NF-B activation. The expression of Nrf2 and HO-1 were increased by treatment of ADH. In conclusion, ADH protected against LPS/D-GaIN-induced liver injury by inhibiting NF-B and activating Nrf2 signaling pathway.

\section{INTRODUCTION}

Acute liver injury is an inflammatory condition that characterized by the sudden loss of hepatic function [1]. It has a high rate of mortality $[1,2]$. LPS has been identified as a major factor that leads to liver injury [3]. Meanwhile, D-GalN has the ability to aggravate LPS-induced liver injury in only in a few hours [4]. Furthermore, LPS and D-GalN-induced mice liver injury model are widely used as experimental animal models to investigate human liver injury [5]. In this model, LPS significantly up-regulates the expression of inflammatory cytokines, such as TNF- $\alpha$ and IL-1 $\beta[6]$. These cytokines can cause serious liver tissue injury such as acute liver injury [7]. Till now, few methods are applied to cure acute liver injury except for liver transplantation [8]. Therefore, developing a high-efficient drug for acute liver injury is pressingly needed. Nrf2 is an important transcription factor that upregulates cytoprotective genes in response to oxidative stress [9]. Previous studies showed that Nrf2 was involved in the development of liver injury [10]. Nrf2 has been identified as a potential target for the treatment of liver injury.

Andrographolide (ADH), an active constitutent isolated from Andrographis paniculata, has been found 
to have anti-inflammatory and antioxidant effects [11]. $\mathrm{ADH}$ has been reported to inhibit LPS-induced acute lung injury in mice [12]. ADH also prevented inflammatory bone loss in vivo [13]. In vitro, $\mathrm{ADH}$ has been reported to inhibit LPS-induced inflammatory mediator production in RAW264.7 cells [14]. ADH also inhibited HMGB1-induced inflammatory responses in human umbilical vein endothelial cells [15]. Previous studies showed that ADH exhibited its anti-inflammatory effects by inhibiting NF- $\mathrm{B}$ activation [16]. However, the protective effects and mechanisms of $\mathrm{ADH}$ on LPS and GalN-induced acute liver injury remain unclear. Therefore, this study takes an attempt to investigate the effects of $\mathrm{ADH}$ on liver injury and reveal its mechanism.

\section{RESULTS}

\section{ADH ameliorates LPS/GalN-induced liver histopathologic changes}

The effects of ADH on LPS/GalN-induced liver histopathologic changes were measured by H\&E staining. The results showed that liver tissues of the control group exhibited an integral hepatic lobular architecture and normal hepatocytes (Figure 1A). However, liver tissues of LPS/DGalN group showed disturbed architecture, including extensive hemorrhage, necrosis and neutrophil infiltration (Figure 1B). These histopathologic changes induced by LPS/D-GalN were significantly inhibited by ADH (Figure 1C, 1D, 1E).

\section{ADH attenuates LPS/GalN-induced serum ALT and AST levels}

The effects of ADH on LPS/GalN-induced serum ALT and AST levels were measured in this study. As shown in Figure 2, there was a marked increase in the production of serum ALT and AST in LPS/GalN group. However, the increases of ALT and AST production induced by LPS/ GalN were significantly inhibited by ADH (Figure 2).

\section{ADH attenuates LPS/GalN-induced MPO, MDA and ROS levels}

To investigate the anti-oxidative effects of $\mathrm{ADH}$, the effects of $\mathrm{ADH}$ on ROS and MDA production were detected in this study. As shown in Figure 3, there was a significant increase in the production of MDA and ROS in LPS/GalN group. However, the increases of MDA and ROS production induced by LPS/GalN were significantly inhibited by ADH (Figure 3). The effects of ADH on MPO activity were detected in this study. As shown in Figure 3, there was a significant increase in the production of MPO in LPS/GalN group. However, the increase of MPO activity induced by LPS/GalN were significantly inhibited by ADH (Figure 3).

\section{ADH inhibits LPS/GalN-induced hepatic TNF-a and IL-1 $\beta$ production}

To investigate the anti-inflammatory effects of $\mathrm{ADH}$, the effects of ADH on inflammatory cytokines TNF- $\alpha$ and IL-1 $\beta$ production were detected in this study. As shown in Figure 4 , there was a marked increase in the production of TNF- $\alpha$ and IL-1 $\beta$ in LPS/GalN group. However, the increases of TNF- $\alpha$ and IL- $1 \beta$ production induced by LPS/ GalN were significantly inhibited by ADH (Figure 4).

\section{ADH inhibits LPS/GalN-induced NF-кB activation}

$\mathrm{NF}-\kappa \mathrm{B}$, a critical transcription factor, has been known to play an important role in the regulation of inflammatory cytokines. To investigate the antiinflammatory mechanism of $\mathrm{ADH}$, the effects of $\mathrm{ADH}$

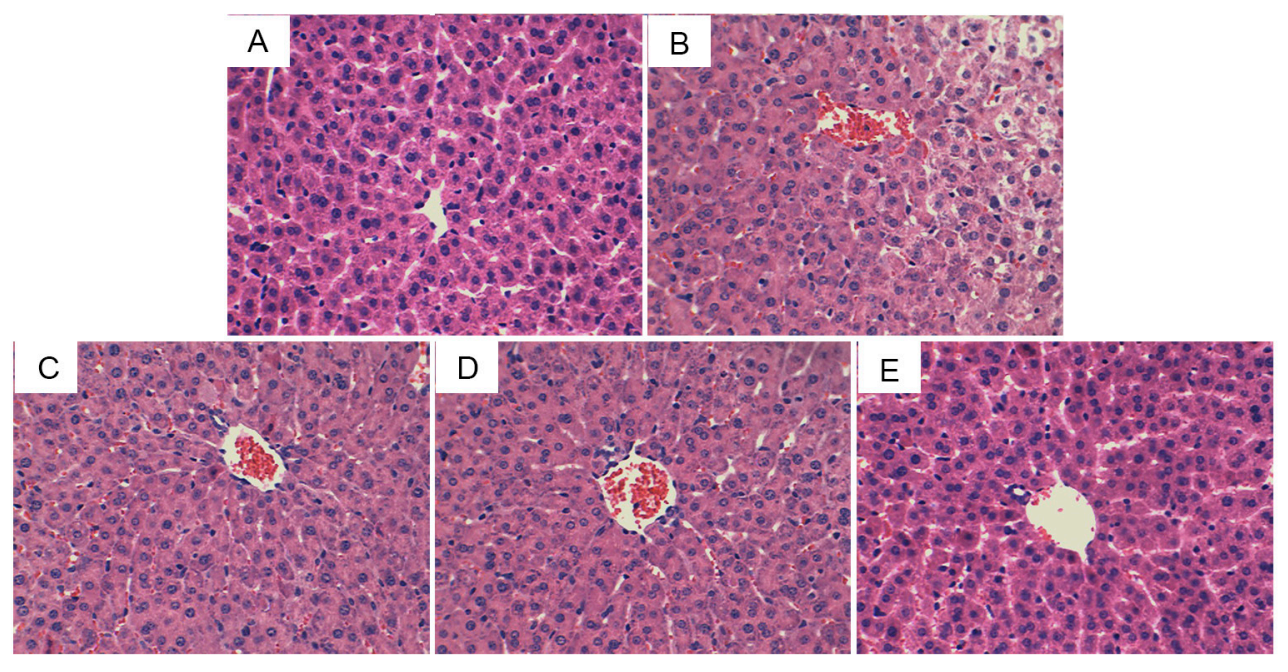

Figure 1: Effects of ADH on histopathological changes in liver tissues. Representative histological changes of liver obtained from mice of different groups. (A) Control group, (B) LPS/GalN group, (C) LPS/GalN + ADH (2.5 mg/kg) group, (D) LPS/GalN + ADH $(5 \mathrm{mg} / \mathrm{kg})$ group, (E) LPS/GalN + ADH (10 mg/kg) group (Hematoxylin and eosin staining, magnification $200 \times)$. 
on LPS/GalN-induced NF- $\mathrm{KB}$ activation were detected in this study. The results showed that LPS/GalN significantly up-regulated the levels of phosphorylation of NF- $\mathrm{KB}$ and I $\mathrm{B} \alpha$. However, treatment of ADH dose-dependently inhibited LPS/GalN-induced NF-kB activation (Figure 5).
Effects of ADH on Nrf2 and HO-1 expression

Nrf2 is a transcription factor implicated in the transactivation of gene coding detoxifying enzymes. To investigate the anti-oxidative mechanism of $\mathrm{ADH}$, the
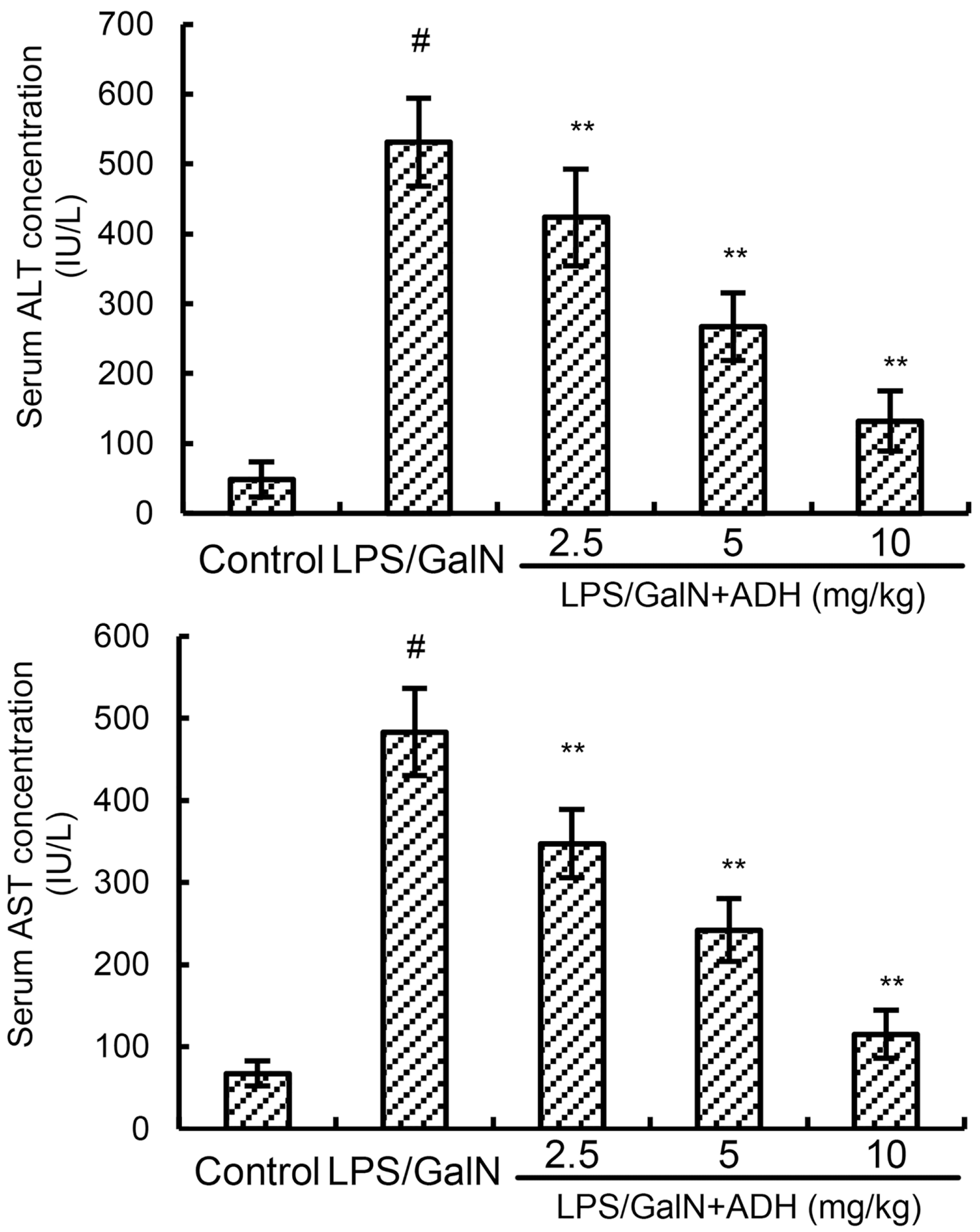

Figure 2: Effects of ADH on serum ALT and AST levels. ADH (2.5, 5, and $10 \mathrm{mg} / \mathrm{kg}$ ) were administered intraperitoneally $1 \mathrm{~h}$ after LPS/GalN treatment. $8 \mathrm{~h}$ after LPS/GalN challenge, the levels of ALT and AST were detected. The values presented are the mean \pm S.E.M. of three independent experiments. $\mathrm{P}^{\#}<0.01$ vs. control group, $\mathrm{P}^{*}<0.05, \mathrm{P}^{* *}<0.01 \mathrm{vs}$. LPS/GalN group.

www.impactjournals.com/oncotarget

41204

Oncotarget 

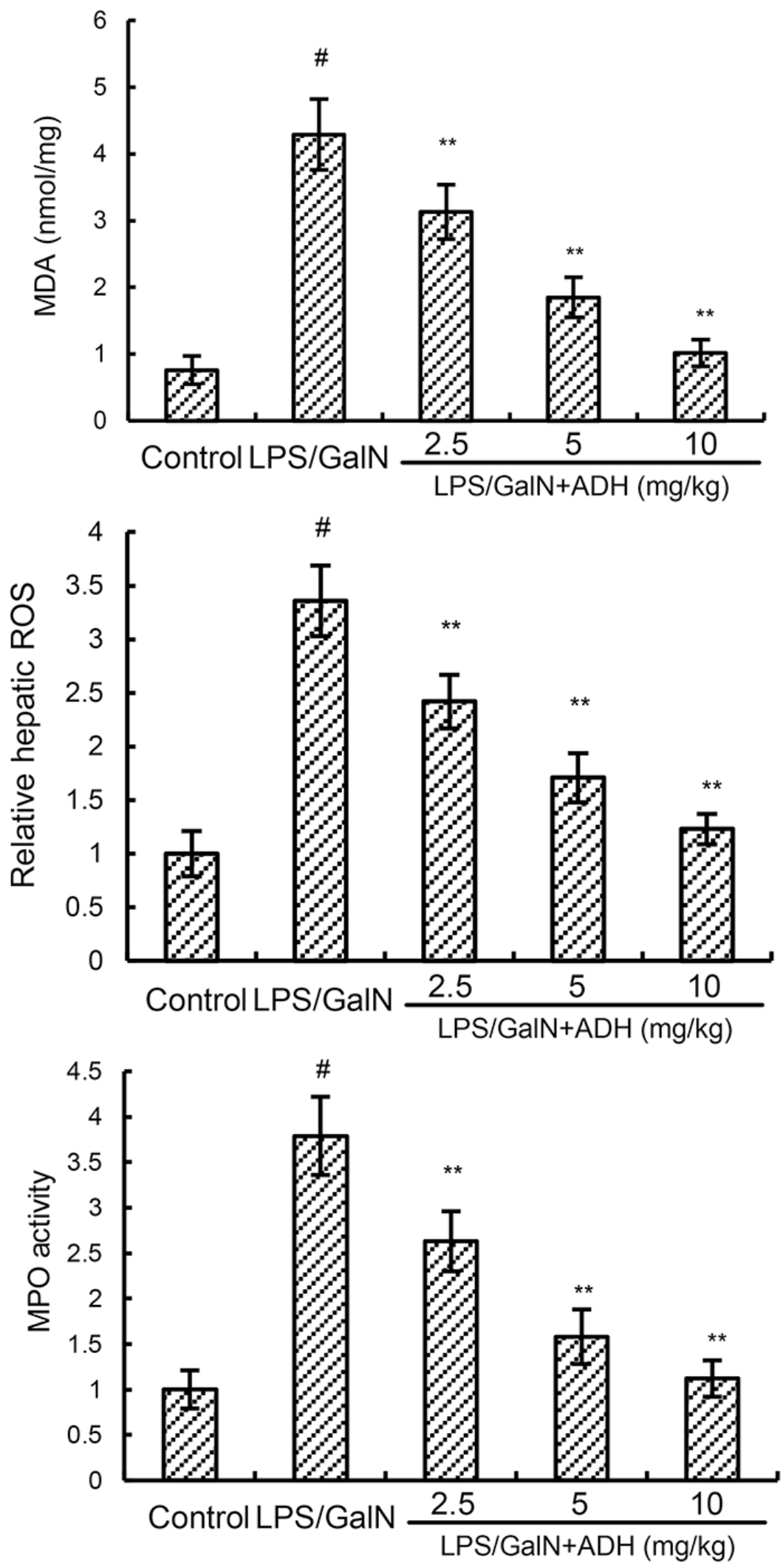

Figure 3: Effects of ADH on liver MPO, MDA, and ROS levels. ADH (2.5, 5, and $10 \mathrm{mg} / \mathrm{kg})$ were administered intraperitoneally $1 \mathrm{~h}$ after LPS/GalN treatment. $8 \mathrm{~h}$ after LPS/GalN challenge, the levels of MDA and ROS were detected. The values presented are the mean \pm S.E.M. of three independent experiments. $\mathrm{P}^{\#<0.01}$ vs. control group, $\mathrm{P}^{*}<0.05, \mathrm{P}^{* *}<0.01$ vs. LPS/GalN group.

www.impactjournals.com/oncotarget

41205

Oncotarget 
effects of ADH on Nrf2 signaling pathway were measured in this study. As shown Figure 6, the expression of Nrf2 and HO-1 were up-regulated by treatment of LPS/ GaIN. However, compared to the LPS/GalN group, the expression of Nrf2 and HO-1 in LPS/GalN + ADH groups increased significantly.
DISCUSSION

Previous studies showed that ADH has antiinflammatory and anti-oxidative effects. In this study, we investigated the protective effects of ADH on LPS/ GalN-induced liver injury. And the results of our present
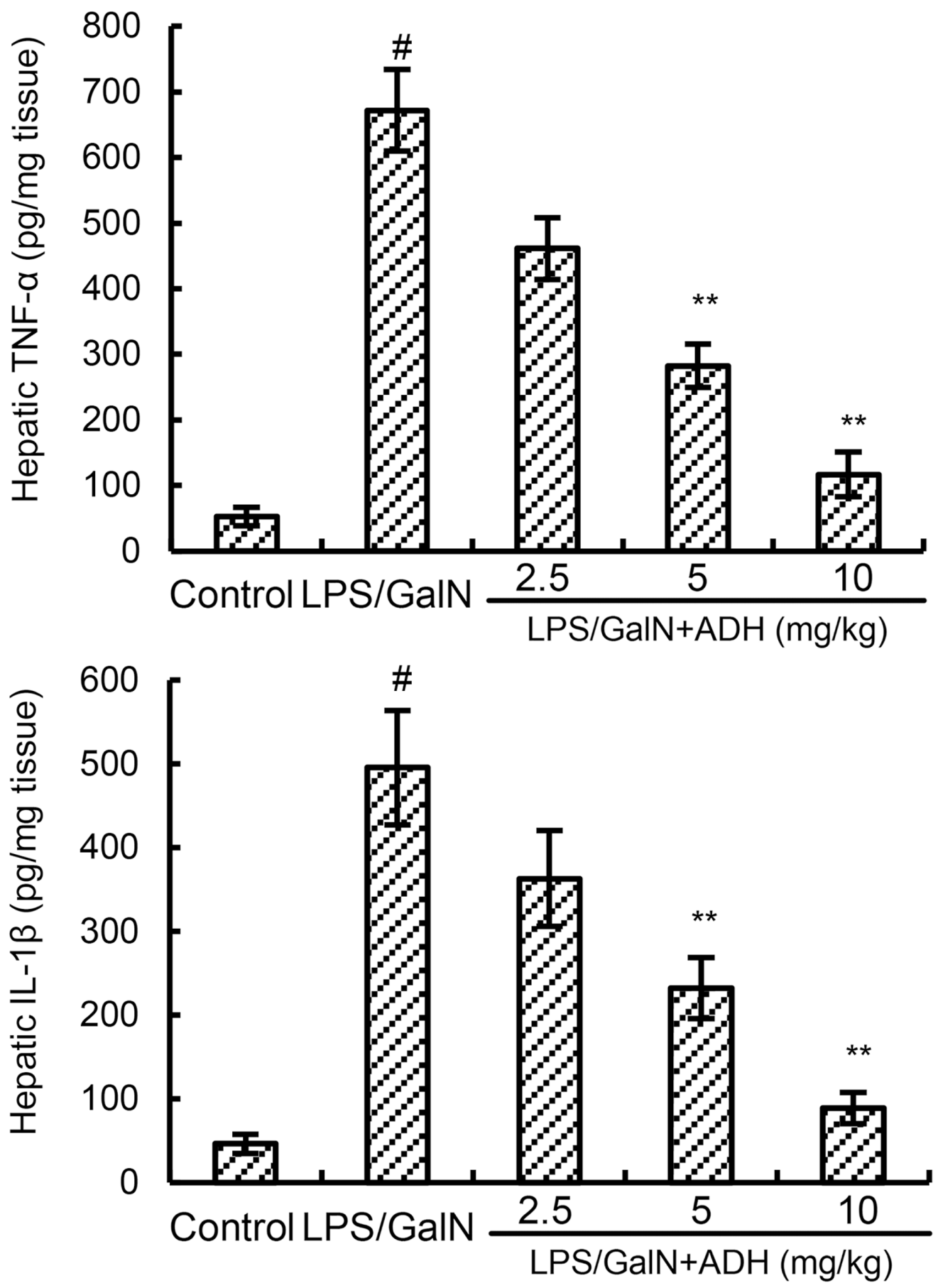

Figure 4: Effects of ADH on hepatic TNF- $\alpha$ and IL-1 $\beta$ levels. ADH (2.5, 5, and $10 \mathrm{mg} / \mathrm{kg})$ were administered intraperitoneally 1 $\mathrm{h}$ after LPS/GalN treatment. $8 \mathrm{~h}$ after LPS/GalN challenge, the levels of hepatic TNF- $\alpha$ and IL-1 $\beta$ were detected. The values presented are the means \pm S.E.M. of three independent experiments. $\mathrm{P}^{\#}<0.01$ vs. control group, $\mathrm{P}^{*}<0.05, \mathrm{P}^{* *}<0.01$ vs. LPS/GalN group.

www.impactjournals.com/oncotarget

41206

Oncotarget 

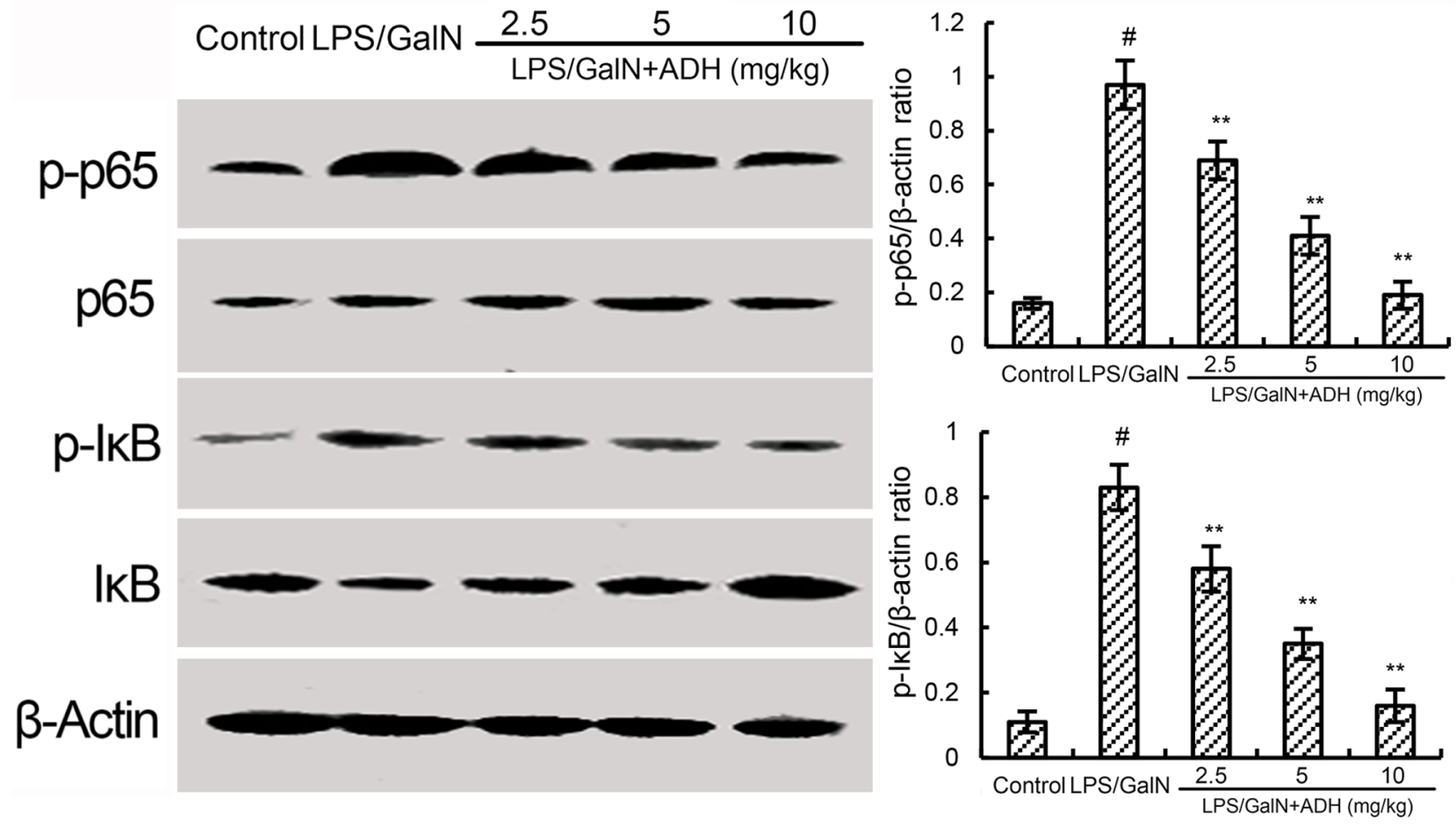

Figure 5: Effects of ADH on LPS/GalN-induced NF-кB activation. ADH (2.5, 5, and $10 \mathrm{mg} / \mathrm{kg}) \mathrm{were}$ administered intraperitoneally $1 \mathrm{~h}$ after LPS/GalN treatment. $8 \mathrm{~h}$ after LPS/GalN challenge, NF- $\kappa \mathrm{B}$ activation were detected. The values presented are the mean \pm S.E.M. of three independent experiments. The density values of the Western blot were normalized for $\beta$-actin. $\mathrm{P}^{\#}<0.01$ vs. control group, $\mathrm{P}^{*}<0.05$, $\mathrm{P} * *<0.01$ vs. LPS/GalN group.

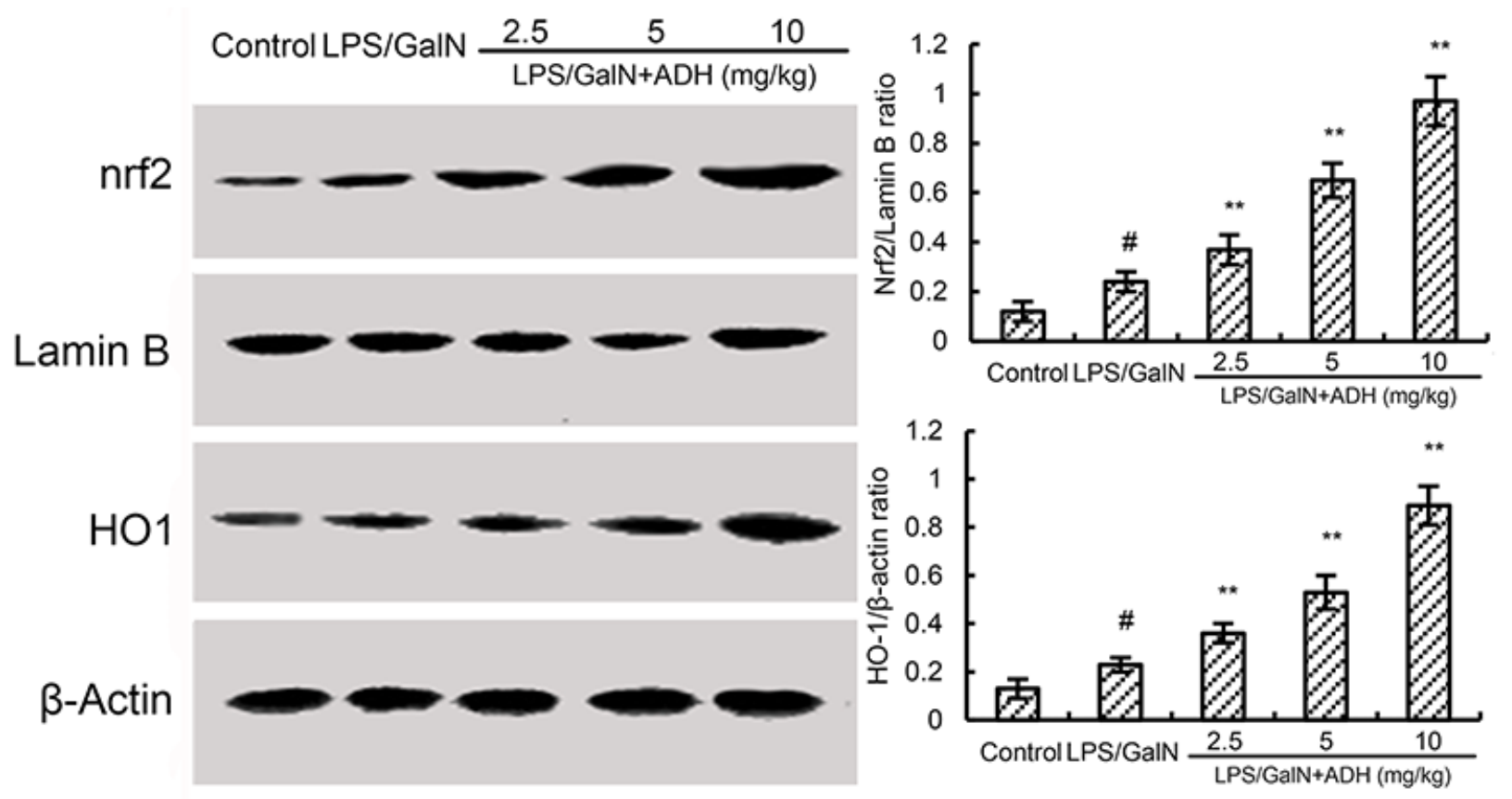

Figure 6: Effects of ADH on Nrf2 and HO-1 expression. ADH (2.5, 5, and $10 \mathrm{mg} / \mathrm{kg})$ were administered intraperitoneally $1 \mathrm{~h}$ after LPS/GalN treatment. $8 \mathrm{~h}$ after LPS/GalN challenge, Nrf2 and HO-1 expression were detected. The values presented are the mean \pm S.E.M. of three independent experiments. The density values of the Western blot were normalized for $\beta$-actin. $\mathrm{P}^{\#}<0.01 \mathrm{vs}$. control group, $\mathrm{P}^{*}<0.05$, $\mathrm{P} * *<0.01$ vs. LPS/GalN group. 
study showed that ADH inhibited LPS/GalN-induced liver injury by inhibiting NF- $\mathrm{B}$ and activating Nrf2 signaling pathway. ADH might be considered as a potential therapeutic reagent for the treatment of liver injury.

LPS/GalN-induced liver injury is characterized by severe inflammatory responses. Elevated inflammatory cytokine productions were observed in mice of LPS/GalNinduced liver injury [17]. These inflammatory cytokines, especially TNF- $\alpha$ and IL- $1 \beta$, have been known to play critical roles in the pathogenesis of liver injury $[18,19]$. Studies showed that inhibition of these inflammatory cytokines could attenuate LPS/GalN-induced liver injury in mice [20]. In this study, we found that ADH significantly inhibited LPS/GalN-induced TNF- $\alpha$ and IL- $1 \beta$ production. $\mathrm{NF}-\kappa \mathrm{B}$ is an important transcription factor that regulates inflammatory cytokine expression during immune and inflammatory responses [21, 22]. Once activation, NF$\kappa \mathrm{B}$ p65 translocates from cytoplasm into the nucleus to regulate inflammatory cytokine expression [23]. Previous studies showed that NF- $\kappa \mathrm{B}$ activation is associated with pathological liver injury-induced by LPS/GalN [24]. Furthermore, many herbal medicines protected against LPS/ GalN-induced liver injury by inhibiting NF- $\kappa \mathrm{B}$ activation $[25,26]$. In this study, we detected whether the antiinflammatory mechanism of $\mathrm{ADH}$ was through inhibiting $\mathrm{NF}-\kappa \mathrm{B}$ signaling pathway. The results of the present study showed that ADH inhibited LPS/GalN-induced liver injury by inhibiting NF- $\kappa \mathrm{B}$ activation. The results suggest that ADH inhibited LPS/GalN-induced inflammatory cytokine production by inhibiting NF- $\kappa \mathrm{B}$ activation.

Oxidative stress also plays an important role in the development of LPS/GalN-induced liver injury [27]. LPS/GalN-induced liver injury is characterized by elevated ROS and MDA levels in liver tissues [28]. In this study, our results showed that ADH significantly inhibited LPS/GalN-induced ROS and MDA production in liver tissues. These results indicated that $\mathrm{ADH}$ could inhibit LPS/GalN-induced oxidative stress in mice. Nrf2 has been reported to play critical roles in the regulation of oxidative response $[29,30]$. Previous studies showed that Nrf2 was involved in the development of liver injury [31]. Nrf2-/- mice showed more severe pathological changes in the liver when the mice were treatment of arsenic [32]. In addition, activating of Nrf2 signaling pathway could inhibit liver injury produced by various hepatotoxicants. Many herbal medicines protected against LPS/GalNinduced liver injury by activating Nrf2 signaling pathway [33]. Nrf2 has been identified as a potential target for the treatment of liver injury [34]. In this study, our results showed that treatment of ADH up-regulated the expression of Nrf2 and HO-1. These results suggested that ADH protected LPS/GalN-induced liver injury by activating Nrf2 signaling pathway.

In conclusion, our results suggested that $\mathrm{ADH}$ had protective effects against LPS/GalN-induced liver injury in mice. The protective effects may be related to the inhibition of inflammatory and oxidative response. ADH inhibited LPS/GalN-induced liver injury by inhibiting NF$\kappa \mathrm{B}$ and activating Nrf2 signaling pathway.

\section{MATERIALS AND METHODS}

\section{Reagents}

ADH (purity $>98 \%$ ) was purchased from the National Institute for the Control of Pharmaceutical and Biological Products (Beijing, China). LPS and GalN were obtained from the Sigma Chemical Co. (L-2880, St. Louis, MO, USA). The kits for biochemical analysis of ALT, AST, and MDA were purchased from the Jiancheng Bioengineering Institute of Nanjing (Nanjing, China). IL$1 \beta$ and TNF- $\alpha$ ELISA kits were purchased from Biolegend (CA, USA). Antibodies against TLR4, p65, p-p65, p-IкB $\alpha$, and $\mathrm{I} \kappa \mathrm{B} \alpha$ were purchased from Santa Cruz Biotechnology (Santa Cruz, CA). The second antibody was provided by Cell Signaling Technology Inc. (Beverly, MA, USA). All other chemicals were of reagent grade.

\section{Animals}

BALB/c mice (6-8 weeks old, weighing approximately 18-22g) were purchased from the Center of Experimental Animals of Wenzhou Medical University (Wenzhou, China). The mice were housed in microisolator cages under a 12/12 h light/dark cycle at $24 \pm 1{ }^{\circ} \mathrm{C}$ and $40-80 \%$ humidity. The mice were fed with food and water ad libitum. All animal experiments were performed in accordance with NIH guidelines for the care and use of laboratory animals.

\section{Experimental protocol}

Sixty mice were divided into five experimental groups ( $\mathrm{n}=10)$ as follows: Control group; LPS/GalN group, LPS/GalN + ADH $(2.5,5$, and $10 \mathrm{mg} / \mathrm{kg})$ groups. Mice were injected intraperitoneally with LPS $(60 \mathrm{mg} / \mathrm{kg})$ and D-GalN $(800 \mathrm{mg} / \mathrm{kg})$ to establish the mice liver injury model [35]. ADH $(2.5,5$, and $10 \mathrm{mg} / \mathrm{kg})$ were administered intraperitoneally $1 \mathrm{~h}$ after LPS/GalN treatment. The blood and liver tissues were collected $8 \mathrm{~h}$ after LPS/GalN challenge for subsequent analysis. The chose of $8 \mathrm{~h}$ after LPS/GalN challenge were based on previous study [36].

\section{Histological examination}

The liver tissues were collected $8 \mathrm{~h}$ after LPS/GalN treatment. Then, the tissue samples were fixed in $10 \%$ buffered formalin for $24 \mathrm{~h}$. The samples were dehydrated with graded alcohol, embedded in paraffin, and sectioned. Finally, the samples were stained with hematoxylin and eosin according to standard procedures.

\section{Biochemical assays}

Blood samples were collected $8 \mathrm{~h}$ after the LPS/GalN challenge. The levels of ALT and AST in serum were detected 
using the detection kits (Jiancheng Bioengineering Institute of Nanjing) according to the manufacturer's instructions. Relative hepatic ROS level was detected as previously described [37]. The content of liver MPO and MDA were detected by using test kits (Jiancheng Bioengineering Institute of Nanjing) according to the manufacturer's protocols.

\section{ELISA assay}

The liver tissues were collected $8 \mathrm{~h}$ after LPS/ GalN treatment. Then the tissues were weighed and homogenized with PBS $(1: 9$, w/v). The levels of inflammatory cytokines TNF- $\alpha$ and IL- $1 \beta$ in the supernatants were detected by ELISA (Biolegend, USA) according to the manufacturer's instructions.

\section{Western blot analysis}

The liver tissues were collected $8 \mathrm{~h}$ after LPS/GalN treatment. Total proteins from liver tissues were extracted with T-PER protein extract kit (Pierce, Rockford, IL, USA) according to the manufacturer's instructions. The concentration of the protein was determined by BCA protein assay kit (Beyotime, China). Equal amounts of protein were separated through $12 \%$ SDS polyacrylamide gels. Subsequently, the proteins were transferred to PVDF membranes. The membranes were blocked with 5\% non-fat milk for $2 \mathrm{~h}$ at room temperature. Then, the membranes were incubated with primary antibodies: TLR4, p65, p-p65, p-I $\mathrm{B} \alpha$, and I $\mathrm{K} \mathrm{B} \alpha$. After washing three times with TBST, the membranes were probed with HRP-conjugated secondary antibody and visualized by the ECL western blotting detection system.

\section{Statistical analysis}

All experimental data were expressed as mean \pm SEM. Multiple comparisons were evaluated by one-way ANOVA the Tukey-Kramer method were used. Statistical significance was defined as $\mathrm{P}<0.05$.

\section{ACKNOWLEDGMENTS}

This work was supported by Zhejiang Provincial Natural Science Foundation of China (LY16H160055, LY17H160054).

\section{CONFLICTS OF INTEREST}

All authors declare that they have no conflict of interest.

\section{REFERENCES}

1. Stravitz RT, Kramer DJ. Management of acute liver failure. Nat Rev Gastroenterol Hepatol. 2009; 6:542-53.
2. Thio CL, Seaberg EC, Skolasky R Jr, Phair J, Visscher B, Muñoz A, Thomas DL, and Multicenter AIDS Cohort Study. HIV-1, hepatitis B virus, and risk of liver-related mortality in the Multicenter Cohort Study (MACS). Lancet. 2002; 360:1921-26.

3. Su GL. Lipopolysaccharides in liver injury: molecular mechanisms of Kupffer cell activation. Am J Physiol Gastrointest Liver Physiol. 2002; 283:G256-65.

4. Canová NK, Martínek J, Kmonícková E, Zídek Z, Kameníková L, Farghali H. Modulation of spontaneous and lipopolysaccharide-induced nitric oxide production and apoptosis by d-galactosamine in rat hepatocyte culture: the significance of combinations of different methods. Toxicol Mech Methods. 2008; 18:63-74.

5. Wan JY, Gong X, Zhang L, Li HZ, Zhou YF, Zhou QX. Protective effect of baicalin against lipopolysaccharide/Dgalactosamine-induced liver injury in mice by up-regulation of heme oxygenase-1. Eur J Pharmacol. 2008; 587:302-08.

6. Nowak M, Gaines GC, Rosenberg J, Minter R, Bahjat FR, Rectenwald J, MacKay SL, Edwards CK 3rd, Moldawer LL. LPS-induced liver injury in D-galactosaminesensitized mice requires secreted TNF- $\alpha$ and the TNF-p55 receptor. Am J Physiol Regul Integr Comp Physiol. 2000; 278:R1202-09.

7. Diehl AM. Cytokine regulation of liver injury and repair. Immunol Rev. 2000; 174:160-71.

8. Pauwels A, Mostefa-Kara N, Florent C, Lévy VG. Emergency liver transplantation for acute liver failure. Evaluation of London and Clichy criteria. J Hepatol. 1993; $17: 124-27$

9. Lee JM, Johnson JA. An important role of Nrf2-ARE pathway in the cellular defense mechanism. J Biochem Mol Biol. 2004; 37:139-43.

10. Xu W, Hellerbrand C, Köhler UA, Bugnon P, Kan YW, Werner S, Beyer TA. The Nrf2 transcription factor protects from toxin-induced liver injury and fibrosis. Lab Invest. 2008; 88:1068-78.

11. Abu-Ghefreh AA, Canatan H, Ezeamuzie CI. In vitro and in vivo anti-inflammatory effects of andrographolide. Int Immunopharmacol. 2009; 9:313-18.

12. Zhu T, Wang DX, Zhang W, Liao XQ, Guan X, Bo H, Sun JY, Huang NW, He J, Zhang YK, Tong J, Li CY. Andrographolide protects against LPS-induced acute

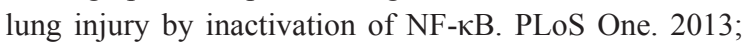
8:e56407.

13. Zhai ZJ, Li HW, Liu GW, Qu XH, Tian B, Yan W, Lin Z, Tang TT, Qin A, Dai KR. Andrographolide suppresses RANKL-induced osteoclastogenesis in vitro and prevents inflammatory bone loss in vivo. Br J Pharmacol. 2014; 171:663-75.

14. Lee KC, Chang HH, Chung YH, Lee TY. Andrographolide acts as an anti-inflammatory agent in LPS-stimulated RAW264.7 macrophages by inhibiting STAT3-mediated suppression of the NF- $\mathrm{BB}$ pathway. J Ethnopharmacol. 2011; 135:678-84. 
15. Lee W, Ku S, Yoo H, Song K, Bae J. Andrographolide inhibits HMGB1-induced inflammatory responses in human umbilical vein endothelial cells and in murine polymicrobial sepsis. Acta Physiol (Oxf). 2014; 211:176-87.

16. Guo W, Liu W, Chen G, Hong S, Qian C, Xie N, Yang X, Sun Y, Xu Q. Water-soluble andrographolide sulfonate exerts anti-sepsis action in mice through downregulating $\mathrm{p} 38 \mathrm{MAPK}$, STAT3 and NF- $\mathrm{\kappa B}$ pathways. Int Immunopharmacol. 2012; 14:613-19.

17. Wang X, Zhang L, Wei Z, Zhang X, Gao Q, Ma Y, Liu X, Jiang Y, Liu X, Guo C, Wang X. The inhibitory action of PDCD4 in lipopolysaccharide/D-galactosamine-induced acute liver injury. Lab Invest. 2013; 93:291-302.

18. Kamo N, Ke B, Ghaffari AA, Shen XD, Busuttil RW, Cheng G, Kupiec-Weglinski JW. ASC/caspase-1/IL-1 $\beta$ signaling triggers inflammatory responses by promoting HMGB1 induction in liver ischemia/reperfusion injury. Hepatology. 2013; 58:351-62.

19. Ghabril M, Bonkovsky HL, Kum C, Davern T, Hayashi $\mathrm{PH}$, Kleiner DE, Serrano J, Rochon J, Fontana RJ, Bonacini M. Liver injury from tumor necrosis factor- $\alpha$ antagonists: analysis of thirty-four cases. Clin Gastroenterol Hepatol. 2013; 11:558-564.e3.

20. Morita T, Jinno K, Kawagishi H, Arimoto Y, Suganuma $\mathrm{H}$, Inakuma T, Sugiyama K. Hepatoprotective effect of myristicin from nutmeg (Myristica fragrans) on lipopolysaccharide/d-galactosamine-induced liver injury. J Agric Food Chem. 2003; 51:1560-65.

21. Fu Y, Hu X, Cao Y, Zhang Z, Zhang N. Saikosaponin a inhibits lipopolysaccharide-oxidative stress and inflammation in Human umbilical vein endothelial cells via preventing TLR4 translocation into lipid rafts. Free Radic Biol Med. 2015; 89:777-85.

22. Li Q, Verma IM. NF-kappaB regulation in the immune system. Nat Rev Immunol. 2002; 2:725-34.

23. Wang J, Guo C, Wei Z, He X, Kou J, Zhou E, Yang Z, Fu Y. Morin suppresses inflammatory cytokine expression by downregulation of nuclear factor- $\mathrm{\kappa B}$ and mitogenactivated protein kinase (MAPK) signaling pathways in lipopolysaccharide-stimulated primary bovine mammary epithelial cells. J Dairy Sci. 2016; 99:3016-22.

24. Heyninck K, Wullaert A, Beyaert R. Nuclear factor-kappa B plays a central role in tumour necrosis factor-mediated liver disease. Biochem Pharmacol. 2003; 66:1409-15.

25. Osakabe N, Yasuda A, Natsume M, Sanbongi C, Kato Y, Osawa T, Yoshikawa T. Rosmarinic acid, a major polyphenolic component of Perilla frutescens, reduces lipopolysaccharide (LPS)-induced liver injury in D-galactosamine (D-GalN)-sensitized mice. Free Radic Biol Med. 2002; 33:798-806.
26. Yoshida T, Abe K, Ikeda T, Matsushita T, Wake K, Sato $\mathrm{T}$, Sato T, Inoue H. Inhibitory effect of glycyrrhizin on lipopolysaccharide and d-galactosamine-induced mouse liver injury. Eur J Pharmacol. 2007; 576:136-42.

27. Sakaguchi S, Furusawa S. Oxidative stress and septic shock: metabolic aspects of oxygen-derived free radicals generated in the liver during endotoxemia. FEMS Immunol Med Microbiol. 2006; 47:167-77.

28. Sheik Abdulazeez S, Thiruvengadam D. Effect of lycopene on oxidative stress induced during D-galactosamine/ lipopolysaccharide-sensitized liver injury in rats. Pharm Biol. 2013; 51:1592-99.

29. Chan K, Han XD, Kan YW. An important function of $\mathrm{Nrf} 2$ in combating oxidative stress: detoxification of acetaminophen. Proc Natl Acad Sci USA. 2001; 98:4611-16.

30. Lamlé J, Marhenke S, Borlak J, Von Wasielewski R, Eriksson CP, Geffers R, Manns MP, Yamamoto M, Vogel A. Nuclear Factor-Eythroid 2-Related Factor 2 Prevents Alcohol-Induced Fulminant Liver Injury. Gastroenterology. 2008; 134:1159-68.

31. Osburn WO, Yates MS, Dolan PD, Chen S, Liby KT, Sporn MB, Taguchi K, Yamamoto M, Kensler TW. Genetic or pharmacologic amplification of nrf2 signaling inhibits acute inflammatory liver injury in mice. Toxicol Sci. 2008; 104:218-27.

32. Jiang T, Huang Z, Chan JY, Zhang DD. Nrf2 protects against As(III)-induced damage in mouse liver and bladder. Toxicol Appl Pharmacol. 2009; 240:8-14.

33. Farombi EO, Shrotriya S, Na HK, Kim SH, Surh YJ. Curcumin attenuates dimethylnitrosamine-induced liver injury in rats through Nrf2-mediated induction of heme oxygenase-1. Food Chem Toxicol. 2008; 46:1279-87.

34. Aleksunes LM, Manautou JE. Emerging role of Nrf2 in protecting against hepatic and gastrointestinal disease. Toxicol Pathol. 2007; 35:459-73.

35. Takano H, Inoue K, Shimada A, Sato H, Yanagisawa R, Yoshikawa T. Urinary trypsin inhibitor protects against liver injury and coagulation pathway dysregulation induced by lipopolysaccharide/D-galactosamine in mice. Lab Invest. 2009; 89:833-39.

36. El-Agamy DS, Makled MN, Gamil NM. Protective effects of agmatine against D-galactosamine and lipopolysaccharide-induced fulminant hepatic failure in mice. Inflammopharmacology. 2014; 22:187-94.

37. Xia X, Su C, Fu J, Zhang P, Jiang X, Xu D, Hu L, Song E, Song Y. Role of $\alpha$-lipoic acid in LPS/d-GalN induced fulminant hepatic failure in mice: studies on oxidative stress, inflammation and apoptosis. Int Immunopharmacol. 2014; 22:293-302. 